Environment Conservation Journal 15(1\&2) 1-3, 2014

ISSN 0972-3099 (Print) 2278-5124 (Online)

Abstracted and Indexed

\title{
GC-MS analysis of essential oil from the rhizomes of Alpinia calcarata Roscoe
}

\section{Manmeet Kaur}

Received: 17.03.2014

Accepted: 19.05.2014

\begin{abstract}
Essential oil from the rhizomes of Alpinia calcarata Roscoe was extracted by hydro-distillation method and characterized by Gas Chromatography-Mass Spectrometry (GC-MS) method. Total 25 compounds were identified and the yield of essential oil was $0.19 \%$. The total identified compounds accounted for about $100 \%$ of the oil. The major identified compounds were Methyl cyclohexane (53.22\%), Fenchyl acetate $(9.14 \%)$ and 1,8 -Cineole $(5.38 \%)$.
\end{abstract}

Keywords: Alpinia calcarata Roscoe, chemical composition, essential oil, GC-MS analysis

\section{Introduction}

Alpinia calcarata Roscoe is an important essential oil yielding perennial herb belongs to Zingiberaceae family. It is widely cultivated in India and commonly known as Indian ginger, Kulanjan and Sugandhamoola (Arambewela and Arawwawala, 2010). It gives essential oil upon steam distillation or hydro-distillation. The rhizomes of Alpinia calcarata Roscoe have several biological activities and used since thousands of years for the treatment of arthritis, inflammation, cough, asthma, chronic bronchitis, indigestion, obesity, fever, cholera, diarrhea, rheumatic pain and malaria. The fine powder of the dried rhizomes of this plant mixed with water has been used orally in a little quantity to improve the immunity of children. Alpinia calcarata Roscoe is reported in Ayurveda as a source of Rasna (taste) and used several Ayurvedic formulations (Joshi et al., 2011), (Prabhu et al., 2012). The flowers of this plant may be picked and seeds have been used for prevent vomiting, colic and diarrhea . Recent studies suggested the antifungal, antioxidant, antiboitic, antidiabetic, analgesic, antiinflammatory, insect repellent, properties of rhizomes essential oil of Alpinia calcarata Roscoe as per Amarbewela et al., 2010), George and Pandalai (1949), Raj et al. (2011), Rahman et al. (2012), Paranagama et al. (2004). The aim of the present study was to identify the chemical constituents of essential oil

\section{Author's Address}

Department of Chemistry, S.M.J.N (PG) College,

Haridwar, UttaraKhand, India

E- mail: manmeet.kaur24@gmail.com extracted from the rhizomes of Alpinia calcarata Roscoe by Gas Chromatography-Mass Spectroscopy (GC-MS) method.

\section{Materials and Methods Collection of Plant Material}

Fresh rhizomes of Alpinia calcarata Roscoe were collected and authenticated from the staff of Dr. Shushila Tiwari herbal garden, Rishikesh, Uttarakhand, India in June, 2013. Fresh rhizomes of the plant were washed with water and dried in shade for 4 weeks.

\section{Extraction of Essential Oil}

$100 \mathrm{~g}$ Dried rhizomes of Alpinia calcarata Roscoe were hydro-distilled for $4 \mathrm{~h}$ by using a Clevengertype apparatus. Thereafter, the oil was extracted from the distillate with n-hexane and dried over anhydrous sodium sulfate. The extracted oil was stored in a dark colored glass bottle until analyzed by Gas Chromatography-Mass Spectrometry method.

\section{Gas Chromatography-Mass Spectrometry} Analysis

GC-MS analysis was done using a Gas Chromatography (FID) coupled with Mass Spectrometer (EI) QP-2010 (Shimadzu Corporation Japan). Rxi-5 Sil MS non polar (30 m length $\mathrm{x}$ $0.25 \mathrm{~mm}$ diameter $\times 0.10 \mu \mathrm{m}$ thickness) capillary column was used. The oven temperature was programmed from $50^{\circ} \mathrm{C}\left(5 \mathrm{~min}\right.$.) to $280^{\circ} \mathrm{C}(10$ min) at $4^{\circ} \mathrm{C} / \mathrm{min}$. The injector temperature was $250^{\circ} \mathrm{C}$ and split injection ratio 1:20. Helium was used as carrier gas at a constant flow rate of 
$0.7 \mathrm{ml} / \mathrm{min} .1 .5 \mu 1$ of the oil diluted with $\mathrm{n}$-hexane was injected. The ionization energy was $70 \mathrm{eV}$, EI mode and ion source temperature was $200^{\circ} \mathrm{C}$. The scan mass range was 40-600 a.m.u. The individual components of the essential oil were identified by computerized matching of their mass spectra with those gathered in the NIST, FFNS and WILEY-MS library of the GC-MS data system and Kovat indices with the literature values.

\section{Results and Discussion}

The Gas Chromatography-Mass Spectrometry analysis of essential oil from the rhizomes of Alpinia calcarata Roscoe is shown on Table 1.

Table1. Chemical constituents of Alpinia calcarata Roscoe essential oil

\begin{tabular}{|l|l|l|}
\hline RT & \% Area & Compound \\
\hline 2.543 & 0.51 & Nonanal \\
\hline $\mathbf{2 . 6 6 3}$ & $\mathbf{5 3 . 2 2}$ & Methyl cyclohexane \\
\hline $\mathbf{2 . 7 1 3}$ & $\mathbf{4 . 0 1}$ & Ethyl cyclopentane \\
\hline 2.753 & 2.40 & $1,2,4-$ Trimethyl cyclohexane \\
\hline 2.813 & 1.70 & $1,2,3-$ Triethyl cyclohexane \\
\hline 2.903 & 0.79 & Isoamyl isobutyrate \\
\hline 2.953 & 2.42 & 2-Methyl heptane \\
\hline 2.980 & 2.48 & Methyl benzene \\
\hline 3.030 & 1.04 & 2,4-Dimethyl hexane \\
\hline $\mathbf{3 . 1 3 0}$ & $\mathbf{3 . 9 4}$ & $\mathbf{1 , 3 - D i m e t h y l ~ c y c l o h e x a n e ~}$ \\
\hline 3.230 & 0.84 & 1,1-Dimethyl cyclohexane \\
\hline 3.270 & 0.37 & 4-Methyl cyclohexane \\
\hline 3.353 & 3.73 & Octane \\
\hline 3.467 & 0.62 & 1,3-Dimethyltrans cyclohexane \\
\hline 3.793 & 0.68 & Hendecane \\
\hline 3.913 & 0.84 & Ethyl cyclohexane \\
\hline 3.987 & 0.28 & 1,1,3-Trimethyl cyclohexane \\
\hline 5.510 & 0.77 & Nonane \\
\hline 6.993 & 0.96 & Camphene \\
\hline $\mathbf{9 . 9 0 3}$ & $\mathbf{5 . 3 8}$ & $\mathbf{1 , 8 - C i n e o l e}$ \\
\hline 13.810 & 0.82 & Camphor \\
\hline 14.680 & 0.64 & Borneol \\
\hline 15.490 & 1.27 & $\alpha$-Terpineol \\
\hline $\mathbf{1 6 . 2 3 0}$ & $\mathbf{9 . 1 4}$ & Fenchyl acetate \\
\hline 26.690 & 1.18 & Carotol \\
\hline & $\mathbf{1 0 0 \%}$ & Total identified constituents \\
\hline & & \\
\hline
\end{tabular}

Result showed that total 25 compounds were identified from the essential oil of the rhizomes of Alpinia calcarata Roscoe by Gas ChromatographyMass Spectrometry analysis. Methyl cyclohexane $(53.22 \%)$, fenchyl acetate $(9.14 \%)$ and 1,8-cineole $(5.38 \%)$ were found as major components, other prominent identified constituents were ethyl cyclopentane $(4.01 \%)$, 1,3-dimethyl cyclohexane (3.94\%), methyl benzene (2.48), 2-methyl heptane $(2.42 \%)$, 1,2,4-trimethyl cyclohexane $(2.40 \%)$, 1,2,3-triethyl cyclohexane $(1.70 \%)$ and carotol $(1.18 \%)$.Intense studies on Alpinia calcarata Roscoe essential oil composition have been already published Kaul et al. (2005), Rout et al. (2005), Bhuiyan et al. (2011).

The essential oils composition determined in this communication showed a relatively similar pattern to those published for other geographical regions: fenchyl acetate (37.6\%), camphene $(13.6 \%)$ and 1,8-cineole (15.6\%) were reported as the major components in essential oil of Alpinia calcarata Roscoe by Kaul et al. (2005), $\beta$-pinene (3.5-4.7\%), camphene (9.0-12.3\%) and 1,8-cineole (15.1-15.5\%), fenchyl acetate (39.1-45.2\%) and geraniol $(0-4.2 \%)$ were reported as the major components by Rout et al. (2005), on the other hand, the Bhuiyan et al (2011) showed fenchyl acetate $(51.34 \%)$ and borneol $(11.44 \%)$ as the main constituents Alpinia calcarata Roscoe rhizomes oil Bhuiyan et al. (2011).

Results of recent studies showed that fenchyl acetate and 1, 8-cineole are the common constituents of all the reported oils of Alpinia calcarata Roscoe worldwide including the present study.

\section{Conclusion}

The essential oil was extracted from the rhizomes of Alpinia calcarata Roscoe by hydro-distillation method and analyzed on Gas ChromatographyMass Spectrometer, Shimadzu QP-2010 (Japan). The major constituents were found methyl cyclohexane $(53.22 \%)$, fenchyl acetate $(9.14 \%)$ and 1,8-cineole $(5.38 \%)$. In conclusion, the essential oil of Alpinia calcarata Roscoe rhizomes may be used for the extraction of two important chemicals; fenchyl acetate and 1,8-cineole. 


\section{References}

Arambewela, L. S. R. and L. D. A. M. Arawwawala, 2010 Standardization of Alpinia calcarata Roscoe Rhizome. Pharmacognosy Res., 2(5): 285-288.

Arambewela, Lakshmi S.R, L.D.A. Menuka Arawwawala, Nandakumara Athauda, 2010 Antioxidant and Antifungal Activities of Essential Oil of Alpinia Calcarata Roscoe Rhizomes., 1 (3): 199-202.

Bhuiyan ,Md. Nazrul Islam, Jaripa Begum, Nemai Chandra Nandi, 2011,Volatile Constituents of Essential Oils Isolated from Different Parts of Alpinia calcarata Rosc. African Journal of Plant Science, 5(15):887-890.

George , M, Pandalai KM. 1949 Investigations on Plant Antibiotics. Indian J Med Res. 37: 169- 81.

Standardization of Alpinia calcarata Roscoe rhizomes

Standardization of Alpinia calcarata Roscoe rhizomes

Standardization of Alpinia calcarata Roscoe rhizomes

Standardization of Alpinia calcarata Roscoe rhizomes

Joshi, Pravin R, Harisha C.R. and Bupesh R. Patel, 2011 Regionally Accepted Popular Source of Ayurvedic Medicinal Plants in Southern India. Int. J. of Pharm. \& Life Sci. (IJPLS), 2 (10): 1123-1132.

Kaul, Pran N, Rajeswara Rao Bhaskarni R, Singh Kamla, Bhattacharya Arun K, Mallavarapu Gopal R, Ramesh Srinivasaiyar, 2005, Volatile Constituents of Essential Oils Isolated from Different Parts of Alpinia Calcarata Rosc. Journal of Essential Oil Research, 17(1):7-9.
Paranagama, Priyani A., and E.M.D. Sujantha Ekanayake, 2004, Repellent Properties from Essential Oil of Alpinia calcarata Rosc. against the American Cockroach, Periplanata Americana. J. Natn. Sci. Foundation Sri Lanka, 32 (1\&2): 1-12.

Prabhu, T. Purushoth, E. Selvakumari1, V.S.Maheswaran, 2012 Pharmacognostical and Preliminary Phytochemical Standardisation of Rhizome Alpinia Calcarata Rosc, IJPI's Journal of Pharmacognosy and Herbal Formulations, 2(8): 30-34.

Rahman, Mizanur, Atiar Rahman, M. A Hashem, M. Ullah, Shakila Afroz and Vidyanath Chaudhary, 2012, Antiinflammatory, Analgesic and GC-MS Analysis of Essential Oil of Alpinia calcarata Rhizome. Int J. Pharm Bio Sci, , 3(4): 55-63.

Raj ,Navin, Sayyed Nadeem, Samir Jain, Chanchal Raj, Kuldeep Chouhan Prithwish Nandi,2011, Ameliorative Effects of Alpinia calcarata in Alloxan-Induced Diabetic Rats. Digest Journal of Nanomaterials and Biostructures 6 (3): 991-997.

Rout, P. K., S. Sahoo, S. P. Rath, Y. R. Rao, 2005, Analysis of the Leaf, Rhizome and Root Oils of Two Accessions of Alpinia calcarata Rosc. Cultivated at Bhubaneswar. Journal of Essential Oil Research, 17 (4):398-400. 